\title{
Agricultural Crowdfunding Risk Prevention and Case Studies: A Case Study of Beijing
}

\author{
He Lin, Li Hua, Wang Zhaoyi, Li Yang, Zhan Linghui \\ Economics \& Management School, Beijing University of Agriculture, Research Base for Beijing New Construction, Beijing, China
}

\section{Email address:}

754458259@qq.com (He Lin), lihuaa1962@126.com (Li Hua)

\section{To cite this article:}

He Lin, Li Hua, Wang Zhaoyi, Li Yang, Zhan Linghui. Agricultural Crowdfunding Risk Prevention and Case Studies: A Case Study of Beijing. Science Innovation. Vol. 6, No. 2, 2018, pp. 59-65. doi: 10.11648/j.si.20180602.12

Received: April 17, 2018; Accepted: June 6, 2018; Published: June 22, 2018

\begin{abstract}
Crowdfunding is one of the development models of Internet finance. With the development of the "crowdfunding+" model, crowdfunding has also been applied to the agricultural sector. Agricultural crowdfunding not only optimizes the agricultural financing environment, but also further releases the vitality of agricultural capital. Based on research conducted by seniors at home and abroad on agricultural crowdfunding, this paper focuses on the research of agricultural crowdfunding risk prevention. This not only can compensate for the lack of research in this field, but also enrich the connotation of internet finance and improve and develop the theory of internet finance risk. Studying the risk of agricultural crowdfunding and analyzing the risks faced by the stakeholders of agricultural crowdfunding are conducive to guiding the support of rational investors in agricultural crowdfunding, the standardization of agricultural crowdfunding platforms, and the standardized review of sponsors of agricultural crowdfunding projects and their projects. This paper takes Beijing as an example to analyze the types of risk, the causes of risk formation and the influencing factors in agricultural crowdfunding. It elaborates the development status of Beijing's agricultural crowdfunding, and conducts a case study on the typical agricultural crowdfunding projects in Beijing. Finally, it puts forward specific development proposals for the prevention of Beijing agricultural crowdfunding, in order to provide theoretical support and practical guidance for the development of Beijing's agricultural crowdfunding and its risk prevention.
\end{abstract}

Keywords: Beijing, Internet Finance, Agricultural Crowdfunding, Risk Prevention, Mechanism

\section{农业众筹风险防范及其案例研究——以北京为例}

\author{
何临, 李华, 王兆怡, 李阳, 詹玲慧
}

北京农学院经济管理学院, 北京新农村建设研究基地, 北京, 中国

邮箱

754458259@qq.com(何临), lihuaa1962@126.com(李华)

摘要：众筹是互联网金融的发展模式之一，随着“众筹+”模式的发展，众筹也被应用到农业领域，农业众筹不仅 优化了农业融资环境, 也进一步释放了农业资本的活力。基于国内外前辈对农业众筹开展的研究, 本文着重于农 业众筹风险防范的研究, 这不仅能弥补该领域研究的不足, 还能丰富互联网金融内涵以及完善和发展互联网金融 风险理论。研究农业众筹风险以及分析农业众筹各方利益主体所面临的风险, 有利于引导农业众筹支持者进行理 性投资、农业众筹平台的规范化建设、农业众筹发起者及其项目的标准化审查。本文以北京为例，剖析了农业众 筹的风险类型、风险形成的原因和影响因素; 阐述了北京农业众筹发展现状; 对北京典型的农业众筹项目进行了 案例分析。最后针对北京农业众筹风险防范提出了具体的发展建议, 以期能够对北京农业众筹的发展及其风险防 范提供理论支撑和实践指导作用。 
关键词: 北京, 互联网金融, 农业众筹, 风险防范, 机制

\section{1. 引言}

农业众筹行业在中国的发展尚不成熟，其发展存在诸 多不足和问题，农业众筹风险问题就是其中一个重要的问 题, 也是值得研究的问题。中国对众筹风险有了一定的研 究, 但是对农业众筹风险的研究还是不足, 今后应该对农 业众筹风险进行更多的研究, 有助于相关利益群体进行农 业众筹的的风险分析。中国对农业众筹风险防范的研究还 处于浅层次, 且研究较少, 没有形成一个研究体系, 应该 进行更深入的研究, 从而建立中国农业众筹风险防范体系 和风险防范机制, 对农业众筹活动进行科学的风险防范指 导。无论是众筹, 还是农业众筹的发展模式都是多元化的, 基于农业众筹多样化的发展模式, 对农业众筹的模式研究, 有助于农业众筹风险防范等其他相关方面的研究, 是农业 众筹其他方面研究的一个理论基础。农业和众筹都有其自 身的特殊性, 农业众筹是农业和众筹的跨界融合 [1], 二者 能够实现融合于双方而言都是能够开辟出一个新的领域, 对农业众筹的研究不仅要了解众筹的特征, 还应该了解农 业的特征, 这样才能对农业众筹领域有一个准确的理论认 识和价值判断。

\section{2. 北京农业众筹发展现状}

\section{1. 农业众筹模式}

权益型农业众筹是指支持者将资金提供给项目发起 者（企业或农户）用以生产开发某种优质特色农产品[2],
在该农产品开始对外销售或已经具备对外销售条件后，项 目发起者按照农业众筹双方的约定，用开发完成的农产品 回报支持者的一种既销售又融资的模式。

股权型农业众筹是指项目发起者允诺让支持者持有 项目或企业的股权, 将支持者变成该项目的股东, 支持者 可以获得股权红利或股权增值等未来收益。

公益型农业众筹是指支持者对农业众筹项目的无偿 捐赠支持[3]。农业领域对公益型众筹的需要是不容忽视的, 比如西北治沙、农村基础设施建设等, 社会公众的力量能 够使社会资源得到更有效的配置。

\section{2. 农业众筹平台}

\subsection{1. 概念}

农业众筹平台即连接农业众筹项目发起者和支持者 的互联网终端[4]。为有创意、有项目的农业众筹项目发起 者提供募资、孵化、运营等农业众筹服务，同时向有农业 投资（或消费）需求的支持者展示农业众筹项目，以满足 农业众筹投融资需求为服务宗旨的一种互联网金融服务 平台。

\subsection{2. 北京农业众筹平台}

目前北京农业众筹平台有PC端平台、APP平台、微信 端平台等形式 [5], 但由于类型多样, 为了有利于统计分析, 此处只列出PC端农业众筹平台, 截止2018年3月21日, 北 京农业众筹平台共上线 5 家，北京设置农业众筹板块的综 合众筹平台共上线有20家[6], 如表1所示。

表1 北京农业众筹平台。

\begin{tabular}{llll}
\hline 类型 & 名称 & 运营状态 & 数量 \\
\hline \multirow{2}{*}{ 农业众筹平台 } & 乐趣来、78众筹 & 运营中 & 2 \\
& 大家种、蜂巢众筹、种筹天下 & 已下线 & 3 \\
& 京东众筹、众筹网、平安众筹网、人人天使、风腺众筹、文筹网、66众筹、欣生活、壹起创、熟人筹 & 运营中 & 10 \\
综合众筹平台 & 多彩云众筹、H基金、安筹网、天下投、我的众筹、优客投、众筹邦、99众筹 & 已下线 & 8 \\
& 共拓网、开拍网 & 已转型 & 2 \\
\hline
\end{tabular}

数据来源: 整理自众筹家, 2018, http://www.zhongchoujia.com

\section{3. 农业众筹项目}

\subsection{1. 概念}

项目是指在一定的约束条件下，具有明确目标的且具有 独一无二特性的一次性活动任务 [7]。基于项目的概念, 农业 众筹项目是指在既定的（既定时间、既定资源、特定主体等） 约束条件下, 进行具有特殊性的并且有明确众筹目标的一次 性开放式众筹融资过程，由于农业众筹回报内容设置的多元 化，一般农业众筹项目会包含两个以上的子项目。

\subsection{2. 北京农业众筹项目}

中国2017年有76670个众筹项目，其中69637个众筹项 目成功, 成功项目融资额达 260 亿元, 北京成功众筹项目 的融资额为 90.59 亿元，约占全国总融资额的 $35 \%[8]$ 。综
合类众筹平台上设置有农业板块，因此农业众筹项目既可 以在农业众筹平台上发起, 也可在综合众筹平台上发起项 目。截止2018年3月25日，此处统计出部分综合众筹平台 和部分农业众筹平台上的农业众筹项目数, 以及所在地是 北京的农业众筹项目数量, 如表 2 所示。

表2 农业众筹项目（单位: 个）。

\begin{tabular}{llll}
\hline 类型 & 平台 & 全国 & 北京 \\
\hline \multirow{5}{*}{ 农业众筹平台 } & 有机有利 & 13446 & 381 \\
& 78众筹 & 14 & 1 \\
& 蜂巢众筹 & 9 & 0 \\
& 乐趣来 & 79 & 7 \\
& 点筹网 & 4329 & 0 \\
& 我筹吧 & 252 & 0 \\
\hline
\end{tabular}




\begin{tabular}{llll}
\hline 类型 & 平台 & 全国 & 北京 \\
\hline \multirow{4}{*}{ 综合众筹平台 } & 众筹网 & 1282 & 119 \\
& 京东金融 & 1183 & 45 \\
& 苏宁金融 & 508 & 0 \\
& 淘宝众筹 & 2683 & 2 \\
\hline
\end{tabular}

数据来源: 整理自相关众筹平台,2018

从农业众筹平台来看，本文列举了6家平台的农业众 筹项目数量情况, 有机有利上全部农业众筹项目数量为 13446 个, 其中项目所在地是北京的农业众筹项目数量为 381 个； 78 众筹上全部农业众筹项目数量为 14 个, 其中项 目所在地是北京的农业众筹项目数量为 1 个; 乐趣来上全 部农业众筹项目数量为个 79 , 其中有 7 个所在地是北京的 农业众筹项目; 蜂巢众筹、点筹网、我筹吧分别上线过 9 个、 4329 个和 252 个农业众筹项目, 其中没有所在地是北 京的农业众筹项目。从综合类众筹平台来看, 本文列举了 4 家平台的农业众筹项目数量情况, 众筹网上全部农业众 筹项目数量为 1282 个, 其中项目所在地是北京的农业众筹 项目数量为 119 个; 京东金融、苏宁金融和淘宝众筹分别 上线过 1183 个、 506 个和 2683 个农业众筹项目，其中农业 众筹项目所在地是北京的分别为 45 个、 0 个和 2 个。不难看 出北京的农业众筹项目发起量不足。

\section{3. 北京农业众筹风险类型}

\section{1. 农业众筹风险}

农业众筹行业的出现为农业的创新发展开辟了一个 新的途径, 而众多成功的农业众筹项目也助推了农业众筹 行业的发展。农业众筹运作过程中潜伏着一定的风险, 依 据农业众筹风险产生的不同原因, 将北京农业众筹的风险 分为农业众筹社会风险、农业众筹市场风险和农业众筹社 会风险。

（1）自然风险。农业发展受多种自然因素的制约, 农业众筹必然是离不开农业的, 农业是农业众筹融资的产 业基础, 农业众筹的自然风险主要体现在农业所面临的自 然风险。农业自然风险是指由于自然界的不规则变化从而 给农业发展造成不可抗力的损失, 即农业发展所受的自然 灾害, 主要体现为出现气象灾害、病害和虫害、地质灾害 等不可抗拒的自然灾害。农业众筹项目实施过程中, 如果 出现地震、滑坡、泥石流、干旱、洪涝等自然灾害事件, 又加之农业自身具有弱质性、不确定性、周期性、渐进性 等特征, 此时农业生产过程会遭受破坏, 从而影响农业众 筹项目相关产品或服务的品质。农业众筹产品或服务的质 量高低直接影响农业众筹回报效率, 如果不能实现对农业 众筹支持者的回报承诺，则宣告农业众筹项目的运作失败。

（2）经济风险。市场经济环境中所涉及的不同的经 济风险纷繁复杂, 农业众筹处在市场经济的大环境之中, 必然是存在经济风险的。一个农业众筹项目的实施无疑是 市场经济环境中的经济活动, 既然是经济活动, 就少不了 经济主体（农业众筹发起者、支持者、平台）对经济利益 的追求, 因此必然就少不了经济风险。
（3）社会风险。社会风险又称为行为风险[9], 农业 众筹社会风险是指参与者的社会行为(包括过失行为、不 当行为及故意行为)或不行为给农业众筹其他相对人所造 成的损失风险。

\section{2. 不同农业众筹主体的风险}

农业众筹在革新农业发展的过程中，一方面让农户、 农民专业合作社、农业企业和跨界新农人等能够利用众筹 发起自己的项目，从而获得一笔农业众筹项目开发的启动 资金, 同时还可以测试农业众筹项目的市场潜力和农产品 的市场需求; 另一方面满足了农业众筹项目支持者对农业 的那一份独特的需求。农业众筹平台作为农业众筹的三要 素之一, 其架起了连接支持者和发起者之间的一座桥梁。 由于农业众筹参与主体的多样性, 本文分别介绍了不同农 业众筹主体所面临的风险。

（1）农业众筹发起者面临的风险。农业众筹发起者 是农业众筹一个重要的风险主体, 农业众筹发起者进行农 业众筹融资需要综合考虑项目质量和内部运营能力, 这是 整个农业众筹融资活动的基础, 农业众筹发起者方面的风 险是指由于农业众筹发起者决策偏差和经营不善导致农 业众筹融资最终失败的风险, 风险主要体现为项目决策风 险、项目执行风险。

（2）农业众筹支持者面临的风险。农业众筹支持者 是否支持某一农业众筹项目、农业众筹支持者能否得到预 期的农业众筹项目回报, 这些不确定性就是农业众筹支持 者所面临的风险。

（3）农业众筹平台面临的风险。农业众筹平台是连 接发起者和支持者的桥梁 [10], 通过对接农业众筹发起者 能够获得所需资金, 支持者也能支持自己中意的农业众筹 项目, 农业众筹平台在农业众筹融资活动中也面临风险。

\section{3. 不同农业众筹模式的风险}

随着农业众筹的发展, 农业众筹的多种模式都在发展, 但是农业众筹运作的过程中, 农业众筹平台的运营、支持 者的投资、发起者的融资、项目的运作等都隐含着不容忽 视的风险。由于农业众筹模式的多样性, 且不同农业众筹 模式自身的特殊性, 本文分别介绍了不同农业众筹模式下 存在的风险。

（1）权益型农业众筹风险。权益型农业众筹项目相 关产品或服务质量与预期不符, 项目发起者则无法实现对 支持者的回报或回报延迟, 这就意味着该农业众筹项目的 执行效率低甚至是不成功的。

（2）股权型农业众筹风险。农业众筹是股权众筹的 重要发展板块, 股权型农业众筹发展已经出具规模, 且具 有较大的发展空间, 但其发展过程中也面临一系列风险, 非法吸收公众存款、非法发行证券的法律风险尤为突出和 明显[11]。

（3）公益型农业众筹风险。公益型农业众筹, 项目 发起者以公益之名发起项目, 为了获得大众的资金支持, 其实质是一种无偿慈善捐赠活动, 支持者一般不会获得回 报。 


\section{4. 北京农业众筹案例分析}

\section{1. 农业众筹项目}

\subsection{1. 农业众筹项目第一期}

名称：【某茶】100块钱，和 90 后一起包1000座茶山。
进度：2015年2月4日发起项目，至2015年3月26日目 标筹资额为 20000 元; 至2015年4月 5 时，筹款超过 $100 \%$, 实际筹资额为 1079351 元, 获得 549 人次支持, 达成预定目 标的 $5397 \%$ 。

子项目：第一期设置的多档子项目如表3所示。

表3 第一期设置的多档子项目。

\begin{tabular}{|c|c|c|}
\hline 支持者支持金额 & 支持者获得的回报 & 回报时间 \\
\hline 无私支持 & 无实质性回报 & / \\
\hline 支持1元 & 从所有 1 块钱参与众筹的人中抽取 $10 \%$ 的幸运支持者, 送出不知名茶一号山头茶宝宝一份, 价值 298 元。 & $\begin{array}{l}\text { 项目成功结束后 } \\
\text { 立即发货 }\end{array}$ \\
\hline 支持100元 & $\begin{array}{l}\text { 大红袍、金骏眉、银骏眉、正山小种、滇红、普洱、六堡茶任选其一, 详见正文; 终生享受茶产品九折 } \\
\text { 优惠; 线下体验点下午茶免一次。 }\end{array}$ & $\begin{array}{l}\text { 项目成功结束后 } \\
\text { 立即发货 }\end{array}$ \\
\hline 支持1000元 & $\begin{array}{l}\text { 大红袍、金骏眉、银骏眉、正山小种、滇红、普洱、六堡茶任意搭配，总价值1000元；终生享受茶产品 } \\
\text { 八五折优线下；体验点下午草五次; ‘新品尝鲜”意外惊喜一份，快递到家。 }\end{array}$ & $\begin{array}{l}\text { 项目成功结束后 } \\
\text { 立即发货 }\end{array}$ \\
\hline 支持 5000 元 & $\begin{array}{l}\text { 大红袍、金骏眉、银骏眉、正山小种、滇红、普洱、六堡茶任意搭配, 总价值 } 4000 \text { 元; 终生享受茶产品 } \\
\text { 八折优惠; 线下体验点下午茶免单 } 8 \text { 次; ‘新品尝鲜’意外惊喜一份, 快递到家; 树龄 } 18 \text { 年的乌龙老枞茶 } 350 \mathrm{~g} \text {, } \\
\text { 价值 } 1800 \text { 元。 }\end{array}$ & $\begin{array}{l}\text { 项目成功结束后 } \\
\text { 立即发货 }\end{array}$ \\
\hline 支持10000元 & $\begin{array}{l}\text { 大红袍、金骏眉、银骏眉、正山小种、滇红、普洱、六堡茶任意搭配, 总价值 } 6000 \text { 元; 终生享受茶产品 } \\
\text { 七折优惠; 线下体验点下午茶免单 } 10 \text { 次; '新品尝鲜, '意外惊喜一份, 快递到家; 树龄 } 18 \text { 年乌龙老枞茶 } 350 \mathrm{~g} \\
\text { 价值 } 1800 \text { 元; 收藏级古树普洱茶生普两饼 } 357 \mathrm{~g} / \text { 饼, 价值 } 1600 \text { 元; 5月初 (茶叶生产时节) 茶乡深度体验 } \\
\text { 三天两夜包吃住行价值 } 4888 \text { 元; 未来茶山度假村项目开发优先合作权。 }\end{array}$ & $\begin{array}{l}\text { 项目成功结束后 } \\
\text { 立即发货 }\end{array}$ \\
\hline
\end{tabular}

数据来源: 众筹网, 2018, http://www.zhongchou.com

\subsection{2. 农业众筹项目第二期}

名称:【某茶】长白山脉已被我们承包, 只差你这个森林之王。

进度：2015年6月23日发起项目，至2015年8月22日目标筹资额为500000元；至2015年6月25日，筹款超过 $100 \%$, 已筹 601066 元, 获得 1331 人次支持; 至2015-08-22 19时, 筹款超过 $100 \%$, 实际筹资额为 3209912 元, 获得 3249 人次支 持，达成预定目标的 $642 \%$ 。

子项目：第二期设置的多档子项目如表4所示。

表4 第二期设置的多档子项目。

\begin{tabular}{|c|c|c|}
\hline 支持者支持金额 & 支持者获得的回报 & 回报时间 \\
\hline 无私支持 & l" & 1 \\
\hline 支持1元 & $\begin{array}{l}\text { 新鲜人参一棵。随机从所有一元支持者中抽取 } 10 \% \text { 幸运名额, 送森林里新挖出来的人参一棵, 享用一杯 } \\
\text { 大补人参茶。 }\end{array}$ & $\begin{array}{l}\text { 项目成功结束后 } \\
20 \text { 天内 }\end{array}$ \\
\hline 支持 100 元 & $\begin{array}{l}\text { 总价值 } 100 \text { 元的桑叶茶、人参茶、丁香红茶、蒲公英红茶、刺五加茶等 } 1000 \text { 个山头, 所有茶类中任选一 } \\
\text { 款; 一次下午茶体验机会, 永久有效; 一次线下体验店免费体验资格, 永久有效。 } \\
\end{array}$ & $\begin{array}{l}\text { 项目成功结束后 } \\
30 \text { 天内 }\end{array}$ \\
\hline 支持360元 & $\begin{array}{l}\text { 承包黄河古道边百年古桑林桑树一棵, 时限一年; 产品回报: 桑叶茶一罐, 桑葚汁一罐, 桑萁干一袋, } \\
\text { 总价值 } 360 \text { 元; 体验回报: 可以在 } 2016 \text { 年春夏之交时节, 亲自前往古桑林, 自己去摘树上剩下的果子, } \\
\text { 体验采制茶; 采摘权出售: 可以帮助支持者以 } 50 \text { 元/棵古桑树的价格将采摘权卖给农民, (PS: 如舍弃 } \\
\text { 体验回报, 可换成等值 } 3000 \text { 元产品回报。) }\end{array}$ & $\begin{array}{l}\text { 项目成功结束后 } \\
360 \text { 天内 }\end{array}$ \\
\hline 支持2000元 & $\begin{array}{l}\text { 总价值 } 1000 \text { 元的桑叶茶、人参、丁香红茶、蒲公英红茶、刺五加茶等 } 1000 \text { 个山头, 所有茶类任意拼配; } \\
\text { 体验回报: } 1 \text { 次实地体验机会or旅行一次 (1人), 价值 } 1600 \text { 元, 永久有效; } 1 \text { 次下午茶体验机会, 永久有 } \\
\text { 效; } 2 \text { 次线下体验店免费体验资格, 永久有效。(PS: 如舍弃体验回报, 可换成等值 } 3000 \text { 元产品回报。) }\end{array}$ & $\begin{array}{l}\text { 项目成功结束后 } \\
60 \text { 天内 }\end{array}$ \\
\hline 支持5000元 & $\begin{array}{l}\text { 总价值 } 2000 \text { 元的桑叶茶、人参、丁香红茶、蒲公英红茶、刺五加茶等 } 1000 \text { 个山头, 所有茶类任意拼配; } \\
\text { 体验回报: } 1 \text { 次实地体验机会or旅行一次 (2-2.5人), 价值 } 3900 \text { 元; } 2 \text { 次下午茶体验机会, 永久有效; } 3 \text { 次 } \\
\text { 线下体验店免费体验资格, 永久有效。(PS: 如舍弃体验回报, 可换成等值 } 3000 \text { 元产品回报。) }\end{array}$ & $\begin{array}{l}\text { 项目成功结束后 } \\
60 \text { 天内 }\end{array}$ \\
\hline 支持10000元 & $\begin{array}{l}\text { 总价值 } 2000 \text { 元的桑叶茶、人参、丁香红茶、蒲公英红茶、刺五加茶等 } 1000 \text { 个山头, 所有茶类中任意拼配; } \\
\text { 体验回报: } 1 \text { 次体验机会or旅行一次 (2-2.5人), 价值 } 3900 \text { 元; 租金回报: 小木屋免费使用一年, 主人不 } \\
\text { 在期间, 森林管家将代为出租给来森林里玩的其他小伙伴收取租金; } 3 \text { 次下午茶体验机会, 永久有效; } 5 \\
\text { 次线下体验店免费体验资格, 永久有效。 (PS: 如舍弃体验回报, 可换成等值 } 3000 \text { 元产品回报。) }\end{array}$ & $\begin{array}{l}\text { 项目成功结束后 } \\
60 \text { 天内 }\end{array}$ \\
\hline 支持50000元 & $\begin{array}{l}\text { 成为山大王, 拥有集团旗下一座山头的命名权和号令权; 连续五年每个季度获得当季新茶两罐; 小木屋 } \\
\text { 一年居住权; 成为联合创始人, 可参加创始人年会; 按照《中华人民共和国合伙人企业法》规定, 签订 } \\
\text { 合伙人协议, 与企业共发展。(PS:每人仅限认购一份。) }\end{array}$ & $\begin{array}{l}\text { 项目成功结束后 } \\
30 \text { 天内 }\end{array}$ \\
\hline 支持100000元 & $\begin{array}{l}\text { 成为山大王, 拥有集团旗下一座山头的命名权和号令权; 连续十年每个季度获得当季新茶两罐; 小木屋 } \\
\text { 两年居住权; 成为联合创始人, 可参加创始人年会; 按照《中华人民共和国合伙人企业法》规定, 签订 } \\
\text { 合伙人协议, 与企业共发展。(PS:每人仅限认购一份。) }\end{array}$ & $\begin{array}{l}\text { 项目成功 } \\
30 \text { 天内 }\end{array}$ \\
\hline
\end{tabular}

数据来源: 众筹网, 2018, http://www.zhongchou.com 


\subsection{3. 农业众筹项目第三期}

名称：【某茶】执子千元，予子千山；一份健康慢递，调养四季生息。

进度：2016年1月28发起项目，至2016年4月27日目标筹资额为 200000 元；至2016年2月1日2时，累计有50人支持， 至2016年2月 1 日3时，累计有 100 人支持; 至2016年3月27日，筹资已达预定目标的 $50 \%$, 至2016年 4 月 27 , 实际筹资额 为 200355 元，达成预定目标的 $101 \%$, 获得 278 人支持。

子项目：第三期设置的多档子项目如表5所示。

表5 第三期设置的多档子项目。

\begin{tabular}{lll}
\hline 支持者支持金额 & 支持者获得的回报 & 回报时间 \\
\hline 无私支持 & 无实质性回报 & $/$ \\
& 健康慢递 (一年期)。一年六次为您寄出适宜当季饮用的新茶、好茶; 每次五种, 全年共计三十种; 来 & 项目成功结束后 \\
支持1000元 & 自深山的神秘好礼，如山茶花、茶油、家酿醋、中草药等; 下午茶免费体验机会一次; “千山旅行”优先 & 立即发货 \\
& 体验权; 亲临茶府衙，结交团队的小朋友及各位山大王。 & \\
\hline
\end{tabular}

数据来源: 众筹网, 2018, http://www.zhongchou.com

\section{2. 项目风险分析}

农业众筹让支持者可以参与农业生产消费过程中的每一个环节，于支持者而言是物质和精神的一个双丰收; 发起 者也是依靠支持者的资金从而开展实施农业众筹项目，农业众筹开创了一个能够让参与者实现互利共赢的局面。该农 业众筹项目非常具有代表性, 整个农业众筹方案不仅涉及了权益型农业众筹, 还涉及到了股权型农业众筹和公益型农 业众筹。该农业众筹项目回报模式如表6所示。

表6 回报模式。

\begin{tabular}{ll}
\hline 模式 & 回报 \\
\hline 权益型农业众筹 & 实物或服务 (桑叶茶、人参、丁香红茶、蒲公英红茶、刺五加茶等; 实地体验机会or森林旅行; 下午茶体验机会; 线下体验 \\
股格。型农业众筹 & 股权分红（成为联合创始人; 按照《中华人民共和国合伙人企业法》规定，签订合伙人协议，与企业共发展。） \\
公益型农业众筹 & 无实物回报（无私支持） \\
\hline
\end{tabular}

数据来源: 众筹网, 2018, http://www.zhongchou.com

农业众筹不仅仅是预售，农业众筹项目的价值值得深 度挖掘, 我们应该熟练的掌握和运用农业众筹为农业服务。 该农业众筹项目的三期众筹都取得了成功，且众筹的金额 在增长，其项目风险防控分析如下:

\subsection{1. 农业众筹发起者}

农业众筹项目发起者以众筹包茶山为核心业务, 通过 众筹包茶山的方式, 减少了茶叶经销的中间环节。农业众 筹项目的模式及回报设置不是属于纯预售模式, 还注重对 农业众筹项目价值的深度挖掘, 增加了支持者的参与感, 农业众筹效果明显。

（1）项目决策的风控。树立了一个众筹包茶山的品 牌, 拥有优质的茶山资源, 部分品类符合欧盟流通标准, 在众筹前期做了大量充分的市场调研工作，启动了中国 30 万座茶山的大普查, 搭建品控实验室, 用“物理标准, 化 学标准, 交通标准, 茶农标准”严苛的企业标准篮选出优 质的茶山。创始人是茶农家庭出身, 她普查了中国的 30 万座茶山, 了解不同时空下产出的不同茶叶。成功案例不 是偶然的, 是项目背后一群人不断工作努力换来的, 农业 众筹前期做了大量的市场调研工作。农业众筹不是救急之 策、也不是“快餐”产品, 众筹项目发起之前的前期准备至 关重要, 大量充分的市场调研, 能够对市场环境进行深入 细致的分析和认知; 另一方面, 用真实的调研数据向支持 者介绍项目, 也更具有说服力。
（2）项目执行的风控。宣传工作到位，精心策划。 项目真实图片、视频资料展示能够让潜在支持者有一个直 观的了解, 其是非常重要的宣传手段; 其次农业众筹事件 的电视、报刊和网络报道也提高了该项目的知名度; 农业 众筹项目文案十分关键, 有逻辑性、清晰性、有说服力和 创新点就能吸引具有好奇心的潜在支持者。

\subsection{2. 农业众筹支持者}

（1）支持风险较低。项目透明度高、可信度高。潜在 支持者通过对发起者提供的项目详情资料, 通过对项目资料 的熟悉了解，从而作出农业众筹决策，农业众筹过程中公布 了土地产权证明、茶山视频、茶叶图片等诸多项目真实资料, 真实可靠的项目资料能够增加潜在支持者的信任度; 农业众 筹子项目回报考虑细致, 比如有一些没法去亲自体验森林生 活的, 会主动提醒到给换成等价值的商品, 细致的考虑使大 家非常的安心放心，没有疑问去参与此次农业众筹。

（2）回报风险可控。一方面项目回报模式新颖，回 报模式包含公益、股权、权益型农业众筹的多种回报模式, 不同子项目都设置了不同的回报模式, 能够让每一个项目 支持者都获得相应的农业众筹回报。如项目众筹成功, 发 起者会及时兄现对支持者承诺的回报; 如项目众筹失败, 众筹网会将众筹款项及时退还项目支持者。

（3）收益分配合理。众筹包茶山, 将茶农与众筹支 持者直接对接, 省去了传统茶叶销售模式中加工商、批发 
商、代理商等中间环节。避免了中间商将利润层层瓜分, 最终将较高的产品价格让消费者买单。茶农可以通过众筹 模式“以销定产”获得更高的收益, 支持者也可以获得物美 价廉的茶, 并且由于整个过程的公开透明, 支持者可以清 楚了解茶叶产自那座山头, 哪家农户种的, 甚至可以亲自 去茶山溯源参观旅游, 了解茶知识和茶文化。

\subsection{3. 农业众筹平台}

农业众筹平台提供农业众筹服务, 致力于通过互联 网、大数据和众筹推动我国农业现代化的发展。

(1) 平台资质有保障。人创咨询发布的《中国众筹平 台评级报告（2017）》将众筹网评为 $\mathrm{A}+$ 级, 众筹网平台在 评级指标中的综合表现最好, 有金融机构、风险投资背景, 资本实力较雄厚; 平台管理团队有丰富的金融、IT工作经 验; 平台运营数据在所有平台中名列前茅; 平台信息披露 较为详细、完备及准确; 平台在风险控制方面比较完善; 品牌影响力大, 新闻曝光度高, 用户评价及行业口碑好。

（2）风险管理。保证金：农业众筹发起者在众筹网 发起的农业众筹项目, 由众筹网作为代收款方, 收取项目 支持者基于项目投资明细单而支付的众筹金额。项目众筹 成功后，众筹网留存项目众筹总金额的 $30 \%$ 作为保证金, 在项目发起者兄现对项目支持者的回报承诺后，众筹网将 该保证金返还给项目发起者。如果项目发起者未兄现对项 目支持者的回报承诺，则众筹网有权直接支配该保证金以 用于兑现对项目支持者的回报承诺。

资金支付渠道费：为保证众筹资金安全，众筹项目项 下资金均通过第三方支付公司代为划转，由此产生的支付 渠道费由项目发起者负担, 项目众筹成功后, 众筹网将扣 除项目众筹总金额的 $3 \%$ 作为资金支付渠道费，并支付给 第三方支付机构。如众筹项目不成功, 则不收取该笔费用。 另, 如众筹项目已众筹成功, 但由于发起者原因无法履行 回报的，发起者需向众筹网支付相当于筹资总金额的 $3 \%$ 的资金支付手续费。

（3）存在一定风险隐患。众筹网网站的用户注册服 务协议中注明众筹网作为众筹信息发布平台, 为项目发起 人及有意为项目提供众筹支持的人提供信息发布服务, 众 筹网仅对项目发起者发起的项目进行形式审查, 不对项目 信息的真实性承担实质性审核责任。

\section{5. 关于北京农业众筹风险防范的建议}

农业众筹风险主要来源于农业众筹平台、农业众筹发 起者和支持者三大主体, 以及受自然条件、经济条件和社 会环境条件的制约, 结合农业众筹不同的运作模式和实际 运作流程, 对于北京农业众筹风险防范的建议, 分别从内 部风险防范和外部风险防范两个方面进行阐述。

\section{1. 建立内部风险防范机制}

随着农业众筹融资规模的不断扩大，如何进行农业众 筹融资的风险防范也越来越受到农业众筹项目参与者的 重视。只有严格控制内部风险的出现, 才有利于农业众筹 融资过程的顺利进行, 农业众筹项目融资过程包括项目筹
备阶段、项目上线阶段以及项目实施阶段三个阶段，农业 众筹风险的防范一般分为事前、事中和事后控制, 可以从 不同的阶段入手针对事前、事中和事后分别给出相应的应 对措施。

（1）农业众筹项目筹备阶段的风险防范，对农业众筹 项目进行优化设计。一个成功的农业众筹项目不是靠想象实 现的, 而是通过大量的市场调研, 充分挖掘项目创意性和论 证项目的可行性, 具有可行性的农业众筹项目才可以实施众 筹。从农业众筹项目的筹备阶段来看, 农业众筹项目本身的 质量和市场价值是农业众筹融资获得成功的一个基础, 发起 者不仅要关注项目本身是否能够获得大众的支持和认可，还 要对项目的目标融资额度、融资期限、展示方式以及对潜在 支持者的回报等切实问题进行充分的论证准备。

（2）农业众筹项目上线阶段的风险防范，设立针对 支持者的激励机制。项目上线阶段，发起者通过农业众筹 平台公开向支持者展示农业众筹创意项目，潜在支持者根 据自身偏好及对项目的评估决定是否给予资金支持。这一 阶段, 发起者的主要任务是完成与潜在支持者的匹配, 尽 可能在最短时间内争取最多的支持者。因此, 激励大众投 资人参与、实现利益相容是本阶段的关键。良好的激励机 制能够降低潜在支持者的参与风险以及利益不一致风险, 是决定农业众筹项目融资成功与否的关键因素。为了实现 大众偏好与农业众筹项目的匹配, 发起者需要充分了解社 会上潜在支持者的参与动机，并制定与之匹配的激励机制。

（3）农业众筹项目实施阶段的风险防范，提升项目 执行能力。项目线上融资成功并非农业众筹的结束。线上 融资成功后, 众筹团队如何管理、农业众筹项目如何实施、 如何兑现对农业众筹支持者的承诺等问题，是农业众筹项 目发起者在项目实施阶段需要解决的关键问题。农业众筹 项目存在自然、市场、社会等多方面的风险, 农业众筹项 目的顺利实施, 一定要保证农业众筹项目所涉及产品或服 务的质量, 可以号召支持者参与到农业众筹项目的实施开 发过程中来, 一方面可以增加支持者的参与感, 另一方面 也是让支持者对农业众筹项目发起者进行项目实施监督。 农业众筹的后续服务问题值得发起者重视，支持者对农业 众筹项目实施和回报环节有任何的质疑, 都应该进行及时 的沟通和处理, 只有维护好与支持者的众筹关系, 才是农 业众筹项目实现可持续发展的一个重要前提。

\section{2. 建立外部风险防范机制}

（1）加快农业众筹平台的规范化建设。农业众筹平 台实现了发起者和支持者的直接对接, 是资金供需双方交 流沟通的一个渠道。从农业众筹项目的申请、审核、发布 到实施，农业众筹平台发挥着不可替代的支持作用[12]， 潜在支持者是否参与农业众筹融资在很大程度上取决于 农业众筹平台的自身平台魅力[13]。北京应加快农业众筹 平台建设, 为农业众筹项目发起者和支持者创造一个良好 的投融资环境。农业众筹平台的发展面临农业众筹行业政 策环境不明朗，农业众筹平台建设不够规范化; 农业众筹 平台数量少、模式发展不均衡; 农业众筹平台地域分布不 平衡; 农业电商众筹平台优势凸出, 农业众筹平台小型创 业企业的发展压力大等一系列问题。 
（2）出台相关扶持政策，并健全农业众筹相关法律 体系。政策环境对农业众筹行业的发展具有较大的影响 [14]，只有农业众筹行业的政策明朗了，才可以让对农业 众筹行业处于观望态度的人免去对政策的担忧, 从而促进 农业众筹行业的发展。农业众筹融资体现了互联网金融的 特征, 是融资民主化、金融市场化的发展方向，对解决农 业众筹项目发起者融资难问题具有独特价值。农业众筹行 业具有不可忽视的行业风险、农业众筹行业法律法规还不 够健全、农业众筹行业的信任度偏低等众多问题的存在。 政府部门也应该通过制定农业众筹相关法律法规[12], 加 强对农业众筹所涉及农产品或服务的质量监管, 以及对农 业众筹平台的监管。需要我们开展农业众筹行业法律法规 健全[15]、提高农业众筹融资监督力度、增强公民对农业 众筹的信任度的一系列工作。

（3）政府农业主管部门加大对农业众筹的宣传推广力 度。农业众筹发展要立足于农业, 其发展难点在于均衡发展, 我们需要解决的问题就是满足农业供需双方的诉求, 通过农 业众筹融资形式达成农业交易, 实现互利共赢。一方面, 北 京居民对农业众筹的了解度较低, 由于没有充分认识和了解 农业众筹，导致农业众筹的参与度较低; 另一方面，农民、 农业企业和农民合作社等对农业众筹的认识不到位, 就不能 利用农业众筹为自己农业融资和营销服务。因此政府农业主 管部门应该加大对农业众筹的宣传推广力度, 增进居民对农 业众筹的了解度和参与度, 从而促进农业众筹行业的发展。

（4）政府有关部门应建立行业监管体系，并培育行 业监管组织。农业众筹是农业金融和营销的一种创新模式, 农业众筹面临自然风险、市场风险和社会风险，且农业众 筹的整个过程中涉及多个环节, 而各个环节都存在较多的 风险点, 因此加强对农业众筹项目实施开发过程的全监管 是有必要的。对农业众筹平台资质、农业众筹项目真实性 和农业众筹项目支持者的权益保护等方面进行监管[16], 建立农业众筹行业监管体系, 从而实现对农业众筹整个融 资过程的全面把控, 确保农业众筹融资过程的规范化操作。

\section{6. 结语}

本文通过学习国内外众筹、农业众筹相关理论知识, 总结该领域已有的科学理论和实践经验, 基于现有研究, 探究农业众筹风险防范领域; 并对北京典型的农业众筹项 目进行案例分析, 进行充分的项目风险分析, 并总结项目 成功的经验和启示。

中国农业众筹支持者对农业众筹的信心还不足，农业 众筹的风险多样且涉及相关利益主体较多, 所以亟需完善 农业众筹风险防范体系和建立农业众筹内外部风险防范 机制。本文总结了农业众筹风险的形成原因和发展规律, 有利于在“互联网+”时代下丰富互联网金融内涵以及完善 和发展互联网金融风险理论; 目前国内外关于农业众筹风 险防范的研究不足, 还没有形成完善的研究体系, 本文在 前人的研究基础上进行了深入的探索, 不仅填补了研究的 空白, 还为农业众筹风险的进一步研究奠定了坚实的基础。 本文所做的研究具有很强的理论意义和实践意义。

\section{致谢}

本文为北京市社会科学基金项目（16JDYJB016）; 家禽产业技术体系北京市创新团队专项(BAIC04-2018); 2017 北京农学院研究生科研创新项目 (5056516005/035) 的阶段性成果之一。

\section{参考文献}

[1] 张雅, 孙晓辉.农业众筹的起源、特点与未来[J].中国农业大 学学报 (社会科学版), 2016（6）：96-105。

[2] 荣娅. 我国农业融资新模式农业众筹研究[D].华南农业大 学,2016。

[3] Debuysere K, Gajda O,Kleverlaan R,etal.A framework for european crowdfunding [J/OL]. [20121029] www. Europecrowdfunding.org/european crowdfunding framework.

[4] 杨晓丽.网络众筹风险分析及其法律规制 [J].铜仁学院学 报,2016,(06):96-98。

[5] 众筹家. 中国众筹平台评级报告（2017） [EB/OL].http://www.zhongchoujia.com/data/28813.html,2018 $-03-21 / 2018-03-22$ 。

[6] 众筹家.平台导航

[EB/OL].http://www.zhongchoujia.com/platform/,2018-03-21 /2018-03-22。

[7] 百度百科. 项目

[EB/OL].https://baike.baidu.com/,2018-02-21/2018-02-22。

[8] 众筹家.中国众筹行业发展年报

[EB/OL].http://www.zhongchoujia.com/data/30373.html/,201 8-03-21/2018-03-22。

[9] 张英杰.互联网众筹风险分析与矫正策略研究 [J].改革与战 略,2016,(09):59-61+150。

[10] Riedl, John. Crowdfunding Technology Innovation [J]. Computer, 2013, 46(3): 100-103.

[11] 唐正伟. 众筹模式风险防范机制研究 [J] 商场现代 化,2014,(21):162-163。

[12] 聂玲, 余增辉.农业众筹法律风险防范研究[J].长春师范大学 学报,2017,(03):44-47。

[13] 孙越. 众筹风险控制问题研究 [J]. 时代金 融,2014,(35):283-284。

[14] 刘辉.互联网金融的风险及防范机制研究 [J]. 中国商 论,2016,(32):30-31。

[15] 黄欣乐,张小龙,刘飞翔.农业众筹的优势、风险及发展对策 探讨[J].福建农业学报,2015,30(09):914-918。

[16] 冯婧婷. 农业众筹的风险控制与防范 [J]. 银行 家,2016,(07):99-101。 